Check for updates

Cite this: RSC Adv., 2018, 8, 35611

Received 29th July 2018

Accepted 9th October 2018

DOI: $10.1039 / c 8 \mathrm{ra06382f}$

rsc.li/rsc-advances

\title{
Effect of pyrolysis temperature on sulfur content, extractable fraction and release of sulfate in corn straw biochar
}

\author{
Baowei Zhao, (D) * Huan Xu, Tao Zhang, Xujun Nan and Fengfeng Ma
}

\begin{abstract}
The contents and release of the nutrient elements N, P and K in biochars have been investigated. Sulfur is an indispensable element for plants, but its content and release in biochar are still unclear. The effect of pyrolysis temperature $\left(300,500\right.$ and $700{ }^{\circ} \mathrm{C}$ ) on the sulfur content, extractable fraction and release of sulfate in corn straw biochars (CS300, CS500 and CS700) was investigated. The biochars were characterized using element analysis, BET, FTIR, and XRD. It was shown that the contents of sulfur in biochars decreased significantly with increasing pyrolysis temperature. The extraction results indicated that the percentages of water extractable-sulfate $\left(\mathrm{W}-\mathrm{SO}_{4}{ }^{2-}\right)$ and organosulfur in biochars decreased while those of $\mathrm{HCl}$ - and $\mathrm{NaH}_{2} \mathrm{PO}_{4}$-extractable sulfate $\left(\mathrm{HCl}-\mathrm{SO}_{4}{ }^{2-}, \mathrm{NaH}_{2} \mathrm{PO}_{4}-\mathrm{SO}_{4}{ }^{2-}\right)$ increased with pyrolysis temperature. Batch release experiments were conducted to test the effect of contact time and addition of Hoagland nutrient solution (HNS) on the release of sulfate from biochars. The release kinetics fitted well with a pseudo-second-order model. Approximately $10.7 \mathrm{mg} \mathrm{g}^{-1}$ of sulfate was released from CS300 during the initial $2 \mathrm{~h}$, whereas 6.32 and $3.93 \mathrm{mg} \mathrm{g}^{-1}$ were released from CS500 and CS700, respectively. Increasing the amounts of HNS led to negative effects on sulfate release. The results indicate that low-temperatures might be optimal for producing biochar from corn straw to improve the sulfur fertilization.
\end{abstract}

\section{Introduction}

Sulfur is an essential and growth-limiting plant nutrient. It is required for protein synthesis, occurs in the form of sulfolipids in photosynthetic membranes and indirectly affects the efficiency of the plant in the use of other plant nutrients. ${ }^{1-3}$ Sulfur plays a key role in processes regulating plant growth, detoxification, defense and resistance. In fact, more recently, sulfur deficiency in plants has been reported in several parts of the world. ${ }^{4}$ Industrial emission laws have gradually decreased the amount of sulfur released into the atmosphere in past decades. This, combined with a growing trend toward non-sulfur based fertilizers, is causing sulfur deficiency in many crops planted in lighter and sandier soils. ${ }^{5}$ The increased sulfur removal from soils under intensive cropping systems and increased crop yields have contributed to sulfur deficiency in plants. As a result, it is becoming increasingly important that more is known about the additives that influence sulfur utility in soils.

Biochar is a by-product of biomass pyrolysis in which the plant-derived materials are heated in the absence of oxygen. It has been suggested as a means to combat climate change and to

School of Environmental and Municipal Engineering, Lanzhou Jiaotong University, Address: No. 88, West Anning Road, Lanzhou 730070, Gansu, P. R. China. E-mail: baowei.zhao@yahoo.com; zhbw2001@sina.com; Fax: +86-931-4956017; Tel: +86931-4938017 achieve agricultural and environmental benefits. ${ }^{6-8}$ If biochar can be used as a soil amendment to improve soil quality and to increase crop production, an obvious positive attribute of biochar is its nutrient value, supplied either directly by providing nutrients to plants or indirectly by improving soil properties, with a consequent improvement in the efficiency of fertilizer use. ${ }^{9}$ Direct nutrient values and the availability of biochar depend on the biomass feedstock and pyrolysis conditions., ${ }^{\mathbf{9}, 10}$ Numerous studies have reported that the addition of biochar to soils could indirectly increase the bioavailability of soil nutrients and improve crop production, such as nitrogen $\left(\mathrm{NH}_{4}{ }^{+}\right.$and $\left.\mathrm{NO}_{3}{ }^{-}\right)$, phosphorus $\left(\mathrm{PO}_{4}{ }^{3-}\right)$ and potassium $\left(\mathrm{K}^{+}\right) .{ }^{11-14} \mathrm{~A}$ few studies have even investigated the potential direct nutrition values of nitrogen and phosphorous in biochars, ${ }^{\mathbf{1 5 - 2 5}}$ where the pyrolysis temperature, ${ }^{15,18-20,23,25}$ source and quality of biomasses $^{20}$ and nutrient composition in biochars ${ }^{15,16,22,24,25}$ were concerned. However, there have been few reports concerning the indirect and direct values of sulfur in biochars, ${ }^{\mathbf{2 6 - 2 8}}$ to our knowledge.

Being similar to other nutrient elements such as nitrogen and phosphorous, it is predicted that biochar itself may be a potential source of sulfur. Direct nutrient values and availability of sulfur in biochars could also depend on pyrolysis conditions according to the present literature. This may be related to changes in the composition of biochar and speciation of sulfur in biochar as the temperature of biochar production 
changes. Cheah et al. reported that corn stover biochars produced under pyrolysis conditions at 500-600 ${ }^{\circ} \mathrm{C}$ contain sulfate, organosulfur, and sulfide. ${ }^{28}$ Knudsen et al. found that $35-50 \%$ of the total sulfur was released to the gas phase during the herbaceous biomass volatilization at $400{ }^{\circ} \mathrm{C}$. Sulfur forms clearly varied as the temperature of the thermal conversion from 500 to $700{ }^{\circ} \mathrm{C}^{26}$ Blum et al. found that speciation rather than the total sulfur of plant litter and corn stover biochar is likely the major factor that influences sulfur mineralization in soil. ${ }^{27}$ These limited results generate interest in finding the quantity of sulfur speciation in biochars produced under different pyrolysis conditions. Moreover, the release of sulfate from biochar produced under different pyrolysis conditions is currently unclear.

In this paper, the biochars were prepared from corn straw at 300, 500 and $700{ }^{\circ} \mathrm{C}$ and characterized using BET, element analysis, FTIR and XRD. The sulfur content, extractable fraction and release of sulfate in biochars were investigated. The overall objectives of the present study are to investigate (i) the influence of pyrolysis temperature on the sulfur content and extractable sulfate fraction in biochars; (ii) the dynamics of $\mathrm{SO}_{4}{ }^{2-}$ release and the effects of other nutrient elements on $\mathrm{SO}_{4}{ }^{2-}$ release from biochars. This investigation can provide detailed information to enable a better understanding of the properties of biochar to be chosen for soil fertilization with sulfur.

\section{Materials and methods}

\section{Chemicals and materials}

Analytical grade sodium sulfate was purchased from Shanghai Chemical Co., China. Deionized water was used in all of the experiments.

The corn straw (CS) was collected from the rural land in Tianshui City, China. It was washed with tap water, and airdried for one week, then crushed into particles using a grinder (FW100, Tianjin Hauxing Instrument Company, China). The element composition of CS is listed in Table 1. The powdered corn straw was tightly placed into a crucible. The filled crucible was covered with a lid. Then, the samples were placed in a muffle furnace (SX2, Shanghai Yuejin Medical

Table 1 Physical and chemical properties of CS300, CS500 and CS700 on dry basis

\begin{tabular}{lrrrr}
\hline Property & \multicolumn{1}{c}{ CS } & CS300 & CS500 & CS700 \\
\hline Composition (\%) & & & & \\
C & 42.61 & 58.83 & 61.75 & 66.39 \\
$\mathrm{H}$ & 6.37 & 3.72 & 1.92 & 0.86 \\
$\mathrm{O}$ & 41.77 & 21.21 & 13.52 & 9.88 \\
$\mathrm{~N}$ & 1.23 & 2.21 & 1.68 & 1.30 \\
$\mathrm{~S}$ & 0.97 & 0.58 & 0.46 & 0.32 \\
Ash & 7.05 & 13.45 & 20.68 & 21.25 \\
& & & & \\
Atomic ratio & & & & \\
$\mathrm{O} / \mathrm{C}$ & 0.75 & 0.36 & 0.22 & 0.15 \\
$\mathrm{H} / \mathrm{C}$ & 1.79 & 0.06 & 0.03 & 0.01 \\
$(\mathrm{O}+\mathrm{N}) / \mathrm{C}$ & 0.78 & 0.40 & 0.25 & 0.17 \\
$\mathrm{pH}$ & - & 9.25 & 9.88 & 10.45 \\
$S_{\mathrm{BET}}\left(\mathrm{m}^{2} \mathrm{~g}^{-1}\right)$ & - & 1.70 & 7.70 & 209 \\
& & & &
\end{tabular}

Instrument Factory, China) to pyrolyze the biomass under an oxygen limited atmosphere. The pyrolysis temperatures were designed as 300, 500 and $700{ }^{\circ} \mathrm{C}$ respectively and the pyrolysis duration was designed as $6 \mathrm{~h}$. After cooling, the obtained biochar was passed through a $0.18 \mathrm{~mm}$ sieve and stored under ambient conditions for the subsequent experiments. The biochars were labeled as CS300, CS500 and CS700.

\section{Characterization}

The total C, N, H, O and S in biochar were determined with an elemental analyzer (Vario EL, Elementar, Germany). The $\mathrm{pH}$ of each biochar was measured using a pH meter with a $1: 2.5(\mathrm{w} /$ w) suspension of the biochar in deionized water. BrunauerEmmett-Teller (BET) surface areas $\left(S_{\mathrm{BET}}\right)$ were obtained from $\mathrm{N}_{2}$ adsorption at $77 \mathrm{~K}$ using a Quantachrome Autosorb-1 (Quantachrome, USA). Organic functional groups present on the surface of biochar were determined by Fourier-transform infrared spectroscopy (FTIR) (NEXUS 670, Thermo Nicolet, USA). X-ray diffraction (XRD) patterns were obtained using a PANalytical instrument (Netherlands) with $\mathrm{Cu} \mathrm{K} \alpha$ radiation at $40 \mathrm{~mA}$ and $40 \mathrm{kV}$.

\section{Sulfate fraction extraction}

We used a wet chemical method similar to that described in ASTM D2492 for the analysis of forms of sulfur. ${ }^{29}$ The inorganic sulfate contents could be detected by these analytical procedures, thus the organic sulfur fraction was calculated by the difference between total sulfur and inorganic sulfur. ${ }^{28}$ Three different extraction procedures were utilized in the detection of the inorganic sulfur: $2.50 \mathrm{~g}$ biochar and $15 \mathrm{~mL}$ of deionized water were placed into a centrifuge tube. The tube was shaken at $145 \mathrm{rpm}$ and $25 \pm 1^{\circ} \mathrm{C}$ on a reciprocating shaker (CHA-S Shaker, Jintan Danyang Instrumental Company, China) for $1 \mathrm{~h}$. The mixture was centrifuged at $4000 \mathrm{rpm}$ for $15 \mathrm{~min}$. The supernatant was removed and sulfate in it was analyzed as water extraction sulfur $\left(\mathrm{W}-\mathrm{SO}_{4}{ }^{2-}\right)$. Then $15 \mathrm{~mL}$ of $0.025 \mathrm{~mol} \mathrm{~L}^{-1}$ $\mathrm{NaH}_{2} \mathrm{PO}_{4}$ was added into the tube. After the same shaking and centrifugation as above, the supernatant was removed and sulfate in it was analyzed as $\mathrm{NaH}_{2} \mathrm{PO}_{4}$ extraction sulfur $\left(\mathrm{NaH}_{2} \mathrm{PO}_{4}-\mathrm{SO}_{4}{ }^{2-}\right)$. At last, $15 \mathrm{~mL}$ of $0.5 \mathrm{~mol} \mathrm{~L}{ }^{-1} \mathrm{HCl}$ was added into the tube. After the same shaking and centrifugation as above, the supernatant was removed and sulfate in it was analyzed as $\mathrm{HCl}$ extraction sulfur $\left(\mathrm{HCl}-\mathrm{SO}_{4}{ }^{2-}\right)$. The extraction solution was filtered with a $0.45 \mu \mathrm{m}$ membrane and measured for $\mathrm{SO}_{4}{ }^{2-}$ amount by indirect atomic absorption spectrometry (AAS). ${ }^{30}$

\section{Sulfate release kinetics}

A biochar sample $(0.050 \mathrm{~g})$ was placed in a $100 \mathrm{~mL}$ Erlenmeyer flask, and $50 \mathrm{~mL}$ of deionized water was added. After being shaken at $145 \mathrm{rpm}$ and $25 \pm 1{ }^{\circ} \mathrm{C}$ on a reciprocating shaker (CHA-S Shaker, Jintan Danyang Instrumental Company, China), the mixture was removed at appropriate time intervals and then filtered with a $0.45 \mu \mathrm{m}$ membrane. The concentration of $\mathrm{SO}_{4}{ }^{2-}$ in each of the supernatants was determined by indirect AAS. Each sample was prepared in triplicate. The amount of $\mathrm{SO}_{4}{ }^{2-}$ 
released from the biochar $q\left(\mathrm{mg}^{-1}\right)$ was calculated from the difference between the initial and equilibrium concentrations of $\mathrm{SO}_{4}{ }^{2-}\left(\mathrm{mg} \mathrm{L}^{-1}\right)$ in solutions, together with the volume of solution (L) and the mass of biochar $(\mathrm{g})$.

\section{Effect of Hoagland nutrient solution on sulfate release}

To study the effect of other nutrient elements on sulfate release, biochar was explored in a similar way at different rates $(10 \%$, $20 \%, 30 \%, 40 \%$ and $50 \%$ ) of modified Hoagland nutrient solutions (HNS). The 100\% modified HNS comprised $4 \mathrm{mmol}$ $\mathrm{L}^{-1} \mathrm{Ca}\left(\mathrm{NO}_{3}\right)_{2}, 6 \mathrm{mmol} \mathrm{L}^{-1} \mathrm{KNO}_{3}, 4 \mathrm{mmol} \mathrm{L}{ }^{-1} \mathrm{KH}_{2} \mathrm{PO}_{4}$, and $1 \mathrm{mmol} \mathrm{L}^{-1} \mathrm{NH}_{4} \mathrm{Cl}$. The results are expressed as the average of three replicates.

\section{Results and discussion}

\section{Characterization of biochar}

The physicochemical properties of the biochars are shown in Table 1 . All properties were strongly influenced by the temperature of pyrolysis. The specific surface areas $\left(S_{\mathrm{BET}}\right)$ of biochars are significantly different and increased in the order of magnitude with pyrolysis temperature, with the values 1.70, 7.70 and $209 \mathrm{~m}^{2} \mathrm{~g}^{-1}$ for CS300, CS500 and CS700. The ash content of biochar increased with increasing pyrolysis temperature from $13.45 \%$ for CS300 to 20.68 and $21.25 \%$ for CS500 and CS700 due to the abundance of mineral elements in corn stalk. ${ }^{31,32}$ The $\mathrm{pH}$ values of biochars exhibited a positive correlation with increasing temperature and ash content. The carbon content remaining in the biochars during pyrolysis increased with temperature. However, the hydrogen, oxygen, nitrogen and sulfur contents decreased. These trends are common with increasing temperature of pyrolysis. $^{32-34}$ As the pyrolysis temperature increased, the atomic ratios of $\mathrm{H} / \mathrm{C}, \mathrm{O} / \mathrm{C}$, and $(\mathrm{O}+$ $\mathrm{N}$ )/C decreased, which indicates that the aromaticity of biochars enhanced while polarity decreased..$^{35}$ The conversion of aliphatic $\mathrm{C}$ to aromatic $\mathrm{C}$ during pyrolysis is accompanied by a reduction in $\mathrm{C}$ mineralization rates. This reduction in mineralization of organic $\mathrm{C}$ also suggests a reduction in the availability of nutrients in biochar that are bound in the organic structure, such as $\mathrm{N}, \mathrm{P}$ and $\mathrm{S} .^{9}$

As seen in Table 1, the sulfur contents decreased from $0.58 \%$ for CS300 to $0.46 \%$ for CS500 and $0.32 \%$ for CS700 with pyrolysis temperature increasing. Cantrell et al. and Al-Wabel et al. also reported decreases in sulfur content with temperature, probably due to loss of sulfur by sulfur-containing volatile organic compounds at $350{ }^{\circ} \mathrm{C} .^{36,37}$ However, Liu et al. and Devi and Saroha observed that sulfur content in biochars remained almost stable throughout the temperature range $300-700{ }^{\circ} \mathrm{C}{ }^{38,39}$ Contrarily, sulfur content increased with increasing pyrolysis temperature was observed for cotton crop residues biochars prepared at $300,400,500$ and $700{ }^{\circ} \mathrm{C}$, which mainly due to low sulfur-containing volatile compounds and/or organic compounds being resistant to sulfur-bond breakages by temperature, and formation of mineral sulfates. ${ }^{32}$

The FTIR spectra of CS300, CS500 and CS700 are presented in Fig. 1. It is obvious that the peak characteristics of main

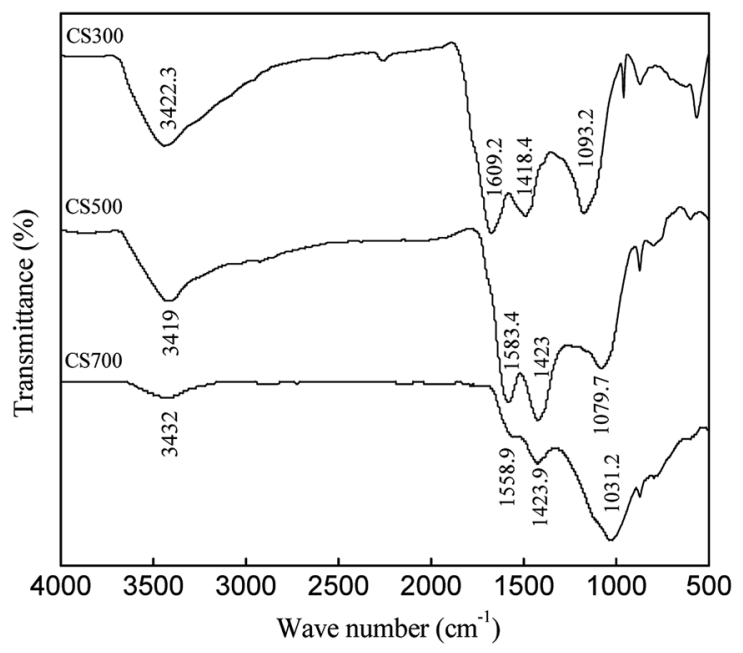

Fig. 1 FTIR spectra of CS300, CS500 and CS700.

functional groups in biochars changed with pyrolysis temperature. The peaks at about $3400 \mathrm{~cm}^{-1}$ associated with $\mathrm{O}-\mathrm{H}$ stretching vibration decreased with pyrolysis temperature. There was stronger $\mathrm{C}=\mathrm{O}$ stretching vibration at $1600 \mathrm{~cm}^{-1}$, indicating the formation of ketones, quinones, and carboxylic C. ${ }^{32}$ However, it declined in CS500 and disappeared in CS700. The peaks at approximately $1420 \mathrm{~cm}^{-1}$ could be attributed to the $\mathrm{C}=\mathrm{C}$ such as olefince and aromatic ring. At the same time the wave numbers of the peaks at $1030-1110 \mathrm{~cm}^{-1}$ associated with dominant $\mathrm{C}-\mathrm{O}$ stretching shifted significantly, suggesting degradation of biomass. ${ }^{32,36}$ The above results indicates that conversion of aliphatic $\mathrm{C}$ to aromatic $\mathrm{C}$ in biochars occurred when the pyrolysis temperature increased.

The XRD spectra of the biochars are shown in Fig. 2. For $\mathrm{CS} 300$, only the presence of $\mathrm{SiO}_{2}$ was confirmed by peaks at $2 \theta=$ $28.244^{\circ}$ and calcite was confirmed by peaks at $2 \theta=36.59^{\circ}$. However, when the pyrolysis temperature was increased, there were more sharp small diffraction peaks for CS500 and CS700, which showed a very well crystal structure and a high content of

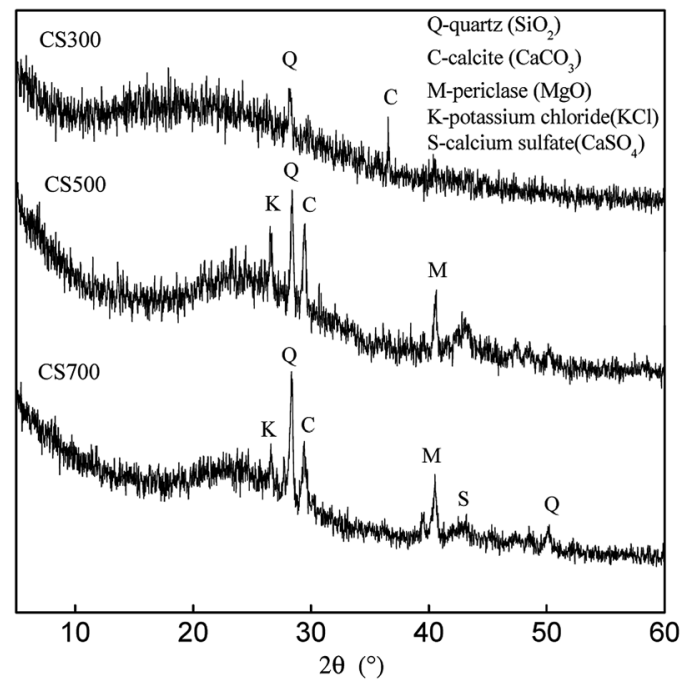

Fig. 2 XRD spectra of CS300, CS500 and CS700. 
mineral components. The intense sharp peak at $2 \theta=29.485^{\circ}$ indicated that calcite was well crystallized where $\mathrm{CaCO}_{3}$ was formed. A weak peak at $2 \theta=43.18^{\circ}$ showed the formation of calcium sulfate $\left(\mathrm{CaSO}_{4}\right)$. This indicates that the increase of pyrolysis temperature is accompanied by the increase of the insoluble sulfate content and salts content in the biochar. The similar results were also obtained for phosphorous in biochars. Bekiaris et al. found that an increase in the pyrolysis temperature led to the formation of a large variety of $\mathrm{P}$ species in biochars. Hydroxyapatite and tricalcium phosphate were the most dominant $\mathrm{P}$ species in the mid to high temperature range (600$\left.900{ }^{\circ} \mathrm{C}\right) .{ }^{22}$ Bruun et al. found that the primary species of $\mathrm{P}$ in bichars derived from solid fraction of manure were simple calcium phosphates. ${ }^{25}$

\section{Extraction forms in biochars}

Fig. 3 shows the distribution of total sulfur content, extractable sulfate and organic sulfur in CS300, CS500 and CS700. With pyrolysis temperature increasing and total sulfur in biochars decreasing, the content of $\mathrm{W}-\mathrm{SO}_{4}{ }^{2-}$ decreased while those of $\mathrm{HCl}-\mathrm{SO}_{4}{ }^{2-}$ and $\mathrm{NaH}_{2} \mathrm{PO}_{4}-\mathrm{SO}_{4}{ }^{2-}$ increased, which can further illustrate the results from XRD. The contents of water-soluble $\mathrm{SO}_{4}{ }^{2-}\left(\mathrm{W}-\mathrm{SO}_{4}{ }^{2-}\right)$ decreased from $0.33 \%$ in $\mathrm{CS} 300$ to $0.18 \%$ in CS500 and then to $0.06 \%$ in CS700. In addition, in CS300 and CS500, the sulfur contents of $\mathrm{W}-\mathrm{SO}_{4}{ }^{2-}$ were much higher than those of $\mathrm{HCl}-\mathrm{SO}_{4}{ }^{2-}$. This could be attributed to the effects of pyrolysis temperature on sulphur form in biochars. Knudsen et al. studied sulphur transformation during pyrolysis of typical Danish wheat straw. Before pyrolysis, sulphur was found to be associated as inorganic sulphate (40 to 50 per cent of total sulfur) and partly as proteins (50 to 60 per cent). At lower temperatures $\left(400{ }^{\circ} \mathrm{C}\right), 35-50$ per cent of the total sulphur was released to the gas phase as a result of decomposition of organic sulphur while inorganic sulphate decreased slightly. At higher temperatures $\left(500{ }^{\circ} \mathrm{C}\right.$ to $700{ }^{\circ} \mathrm{C}$ ), the residual sulphur contents of biochar did not change significantly. However, the forms of sulphur changed, with a disappearance of inorganic sulphate

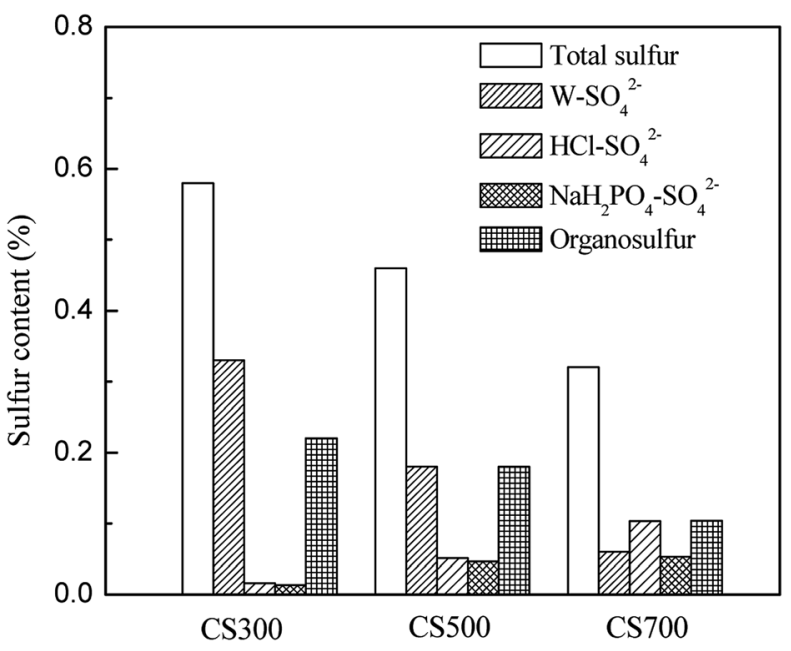

Fig. 3 Contents of total sulfur, extractable sulfate and organosulfur in CS300, CS500 and CS700. due to the conversion to insoluble sulphide or from fixed to reactive biochar surfaces by either addition of sulphur to unsaturated sites or by substitution of oxygen in surface oxides. $^{26}$ The results reported by Cheah et al. indicated that there is more sulfate in the corn stover $500{ }^{\circ} \mathrm{C}$ biochar than the corn stover $850{ }^{\circ} \mathrm{C}$ biochar even when accounting for sample heterogeneity, i.e. 63 and $17 \%$ sulfate species for the corn stover biochar produced at 500 and $850{ }^{\circ} \mathrm{C}$, respectively. The elements in biomass that are likely bound to sulfur in the sulfate form are $\mathrm{Ca}, \mathrm{K}, \mathrm{Mg}$, and $\mathrm{Na}^{28}$ According to thermodynamic calculations published in the literature, silicate may compete with sulfate for these cations. ${ }^{40}$ Therefore, even though there are high concentrations of metals, such as potassium and calcium in corn stover, they may not be able to capture much of the sulfur. This would result in more sulfur being released to the syngas, a phenomenon often reported for herbaceous feedstocks. ${ }^{26,40}$ Because the stability of silicate is higher than that of sulfate at higher temperatures, silicate is able to sequester even more of the inorganic cations, resulting in a lower $\mathrm{W}-\mathrm{SO}_{4}{ }^{2-}$ concentration in CS700 and CS500 than in the CS300.

The different forms of sulfur in biochar led to different percentages released. Low-temperature biochar has more sulfate that is immediately and more readily available to the plant. Schneider and Haderlein found that in two slightly acidic hydrochars derived from sewage sludge, most $\mathrm{P}$ was associated with $\mathrm{Fe}$ and was extractable by $0.1 \mathrm{~mol} \mathrm{~L}^{-1} \mathrm{NaOH}$ while in the remaining alkaline pyrochars most $\mathrm{P}$ was associated with $\mathrm{Ca}$ and was extractable by $1 \mathrm{~mol} \mathrm{~L}^{-1} \mathrm{HCl}^{.24}$ Mukherjee and Zimmerman found that the release of $\mathrm{N}$ and $\mathrm{P}$ from biochars into water was correlated with both the volatile-matter content and acid functional-group density of biochars. ${ }^{\mathbf{1 6}}$ Bruun et al. also found that the low availability of $\mathrm{P}$ in the biochar produced at high temperatures can likely be explained by the formation of less-soluble $\mathrm{P}$ species in the biochar. ${ }^{25}$

The organic sulfur decreased from $0.22 \%$ in CS300 to $0.16 \%$ in CS500 and then to $0.1 \%$ in CS700 (Fig. 3). Much of the organosulfur was believed to be found in the proteins. The decomposition temperatures of the sulfur-bearing amino acids such as cysteine and methionine are 178 and $283^{\circ} \mathrm{C}$, respectively. ${ }^{41}$ It is further suggested that the initial sulfur release is caused predominantly by decomposition of organosulfur. The contents of different forms of sulfur may be ruled by a temperature-dependent pattern, which suggests that the pyrolysis temperature is one of the determining factors of sulfur speciation in the biochar.

\section{Effect of time on sulfate release}

The results of $\mathrm{SO}_{4}{ }^{2-}$ release kinetics experiments on biochars are shown in Fig. 4. The $\mathrm{SO}_{4}{ }^{2-}$ release from biochars mainly occurred within $2 \mathrm{~h}$, followed by a slow increase (less than $5 \%$ ) from 2 to $20 \mathrm{~h}$, showing that these biochars contain rapidly released $\mathrm{SO}_{4}{ }^{2-}$. Approximately $10.7 \mathrm{mg} \mathrm{\textrm {g } ^ { - 1 }}$ of sulfate was released from CS300 in the initial $2 \mathrm{~h}$, whereas 6.32 and $3.93 \mathrm{mg}$ $\mathrm{g}^{-1}$ were released from CS500 and CS700. After $2 \mathrm{~h}$, the release of $\mathrm{SO}_{4}{ }^{2-}$ levelled off. The similar pattern was also observed by Qian et al., for $\mathrm{P}$ release from biochars made from rice husks. 


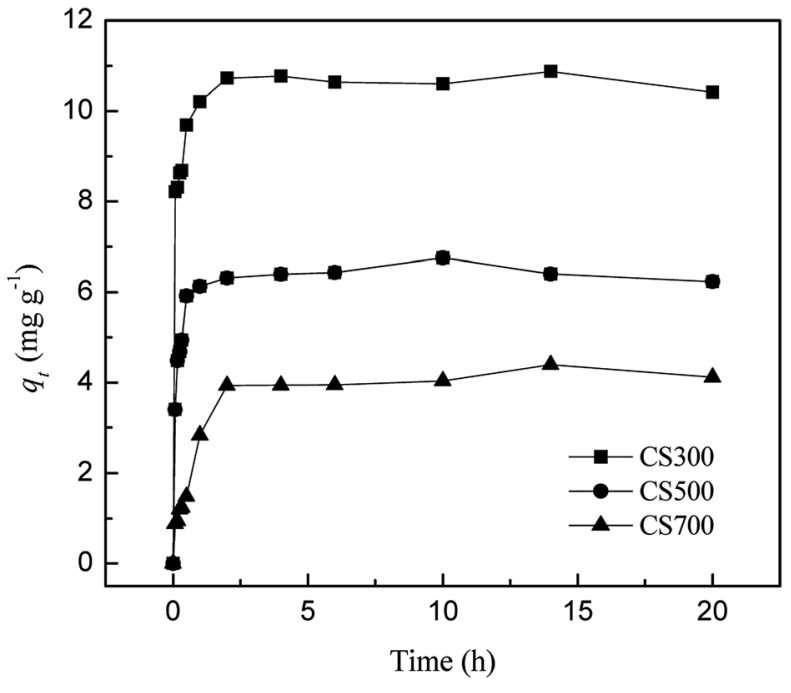

Fig. 4 Plots of released amounts of $\mathrm{SO}_{4}{ }^{2-}$ in CS300, CS500 and CS700 versus time.

When used in field situations, the $\mathrm{SO}_{4}{ }^{2-}$ forms supplied by the biochars prepared at low temperature would be readily available for plant uptake. ${ }^{17}$ Thus, these biochars could be useful to augment crop fertilizer needs. Mukherjee and Zimmerman found that, in successive batch extractions of biochar, cumulative losses were approximately $0.1-2,0.5-8$ and $5-100 \%$ of the total $\mathrm{C}, \mathrm{N}$ and $\mathrm{P}$ initially present, respectively, with greater releases from biochars made from grass at lower temperature. ${ }^{\mathbf{1 6}}$

Using pseudo-first-order (1), pseudo-second-order (2), and power-law (3) models, the release kinetics of $\mathrm{SO}_{4}{ }^{2-}$ from biochars are examined and can be expressed by the following equations:

$$
\begin{gathered}
\ln \left(q_{\mathrm{e}}-q_{t}\right)=\ln q_{\mathrm{e}}-k_{1} t \\
t / q_{t}=1 / k_{2} q_{\mathrm{e}}^{2}+t / q_{\mathrm{e}} \\
q_{t}=a t^{b}
\end{gathered}
$$

where $q_{\mathrm{e}}$ and $q_{t}\left(\mathrm{mg} \mathrm{g}^{-1}\right)$ are the release capacities at equilibrium and at time $t(\mathrm{~h})$, respectively; $k_{1}\left(\mathrm{~h}^{-1}\right), k_{2}\left(\mathrm{~g} \mathrm{mg}^{-1} \mathrm{~h}^{-1}\right)$, $a\left(\left(\mathrm{mg} \mathrm{g}^{-1} \mathrm{~h}^{-1}\right)^{b}\right)$ and $b\left(\mathrm{mg}^{-1} \mathrm{~g}^{-1}\right)$ are constants that relate to the concentration of $\mathrm{SO}_{4}{ }^{2-}$ released.

The kinetic data were fitted using three kinetic models to understand the processes governing $\mathrm{SO}_{4}{ }^{2-}$ release from biochars (Table 2). The $R^{2}$ values of the pseudo-second-order model for release of $\mathrm{SO}_{4}{ }^{2-}$ from biochars ranged from 0.987 to 0.997 , which are higher than those of the power model and the pseudo-first-order model. Moreover, the calculated release capacity values of $\mathrm{SO}_{4}{ }^{2-}\left(q_{\mathrm{e}, \mathrm{cal}}\right)$ from the pseudo-second-order model are closer to the experimental results $\left(q_{\text {e,exp }}\right)$. Thus, the pseudo-second-order model provides the best fit with the experimental data. This suggests that the rate-limiting step of $\mathrm{SO}_{4}{ }^{2-}$ release might be the chemical interaction between sulfur and the biochar surface. The correlation coefficients $\left(R^{2}\right)$ for the power function were all above 0.8 and can be a good choice for describing the release kinetics of $\mathrm{SO}_{4}{ }^{2-}$ from biochars. The two
Table 2 Kinetic model parameters for $\mathrm{SO}_{4}{ }^{2-}$ releasing from biochars

\begin{tabular}{llcll}
\hline Parameter & & CS300 & CS500 & CS700 \\
\hline$q_{\mathrm{e}, \text { exp }}\left(\mathrm{mg} \mathrm{L}^{-1}\right)$ & & 10.82 & 6.08 & 4.03 \\
Pseudo-first-order & $k_{1}\left(\mathrm{~h}^{-1}\right)$ & 0.18 & 0.22 & 1.10 \\
& $q_{\mathrm{e}, \mathrm{cal}}\left(\mathrm{mg} \mathrm{L}^{-1}\right)$ & 3.52 & 1.98 & 3.81 \\
& $R^{2}$ & 0.735 & 0.957 & 0.943 \\
Pseudo-second-order & $k_{2}\left(\mathrm{~g} \mathrm{mg}^{-1} \mathrm{~h}^{-1}\right)$ & 0.85 & 2.30 & 5.53 \\
& $q_{\mathrm{e}, \mathrm{cal}}\left(\mathrm{mg} \mathrm{L}^{-1}\right)$ & 10.86 & 6.59 & 4.25 \\
& $R^{2}$ & 0.988 & 0.997 & 0.987 \\
Power & $a\left(\mathrm{mg} \mathrm{g}^{-1} \mathrm{~h}^{-1}\right)^{b}$ & 2.75 & 2.01 & 1.41 \\
& $b\left(\mathrm{mg}^{-1} \mathrm{~g}^{-1}\right)$ & 0.24 & 0.36 & 0.68 \\
& $R^{2}$ & 0.814 & 0.843 & 0.852
\end{tabular}

parameters of the power function can be viewed as indicators of the initial concentration of $\mathrm{SO}_{4}{ }^{2-}$ release $(a)$ and the rate at which the release of nutrients declines with time $(b) .{ }^{42}$ Generally, for $\mathrm{SO}_{4}{ }^{2-}$, the parameters $a$ and $b$ decreased and increased with temperature, respectively, suggesting that lower amounts of $\mathrm{SO}_{4}{ }^{2-}$ were released from biochars produced at high temperatures. Biochars containing mineral matter (ash) produced at low temperatures have a much greater concentration of sub-grain boundaries and defects on the surface than the same biochars produced at high temperatures. Mineral matter in low-temperature biochars is more likely to dissolve since these defects are centers for reactions with liquids and gases. These changes should have effects on the total nutrient content as well as their availability. ${ }^{9}$

\section{Effect of Hoagland nutrient solution on sulfate release}

If biochar is applied as one of the additives in soil to supply sulfur, it is vital to consider the effect of other nutrient elements on the release of sulfur. Thus, the influence of different additions $(10 \%, 20 \%, 30 \%, 40 \%$ and $50 \%)$ of the modified Hoagland nutrient solution (HNS) on the release of sulfur was investigated. There was a negative correlation between the amount of released sulfate and the modified HNS concentration (Fig. 5).

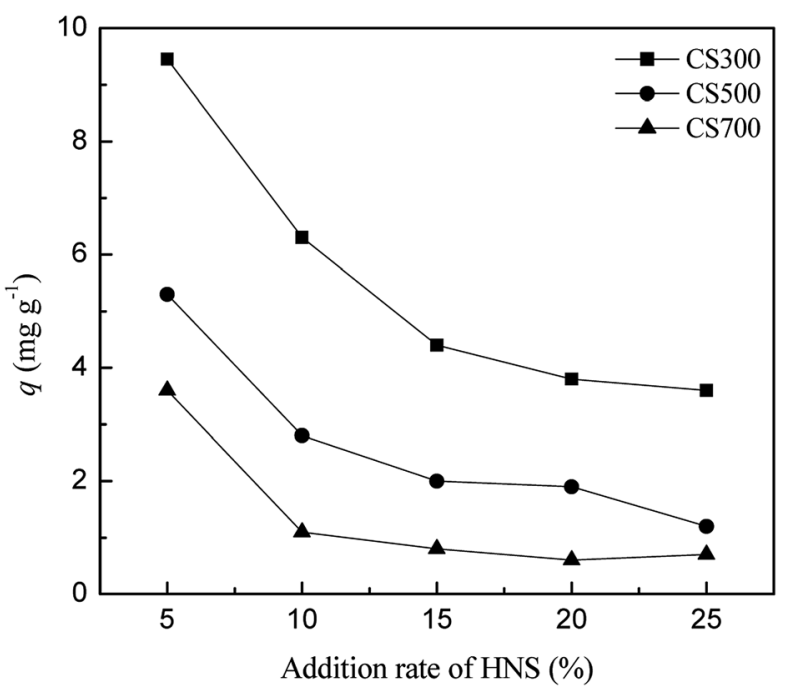

Fig. 5 Plots of released amounts of $\mathrm{SO}_{4}{ }^{2-}$ in CS300, CS500 and CS700 versus addition rate of HNS. 
The drastic decreases in sulfur released from CS300 (from 9.5 to $6.3 \mathrm{mg} \mathrm{g}^{-1}$ ), CS500 (from 5.3 to $2.8 \mathrm{mg} \mathrm{g}^{-1}$ ) and CS700 (from 3.6 to $1.1 \mathrm{mg} \mathrm{g}^{-1}$ ) were observed when the addition rates increased from $5 \%$ to $10 \%$. The possible reason for the decrease in sulfate release could be that the increased amount of cation $\left(\mathrm{Ca}^{2+}\right)$ in the modified HNS reacted with $\mathrm{SO}_{4}{ }^{2-}$ to form $\mathrm{CaSO}_{4}$ on the biochar surface and are difficult to release again. Qian et al. found that the introduction of Hoagland nutrient solution led to the decrease in the release of $\mathrm{P}$ in biochars due to the formation of precipitates between dissolved $\mathrm{P}$ and excessive $\mathrm{Ca}^{2+}$ and $\mathrm{Mg}^{2+} \cdot{ }^{17}$

\section{Conclusions}

The total sulfur content in CS300 was higher than those in CS500 and CS700. The contents of inorganic sulfate also had a temperature-dependent pattern, which suggest that the pyrolysis temperature is an important factor influencing the form of sulfur in the biochar. The release kinetics could be wellfitted with a pseudo-second-order model. The introduction of Hoagland nutrient solution (HNS) led to the decrease in the release of water-soluble sulfate due to the formation of precipitates between dissolved sulfate and excessive $\mathrm{Ca}^{2+}$. The results indicate that low temperatures might be optimal for producing biochar from corn straw to improve the use of sulfur as a fertilizer.

\section{Conflicts of interest}

There are no conflicts to declare.

\section{Acknowledgements}

This research was financially supported by the National Natural Science Foundation of China (21467013, 21167007, 51766008), and the Specialized Research Fund for the Doctoral Program of Higher Education of China (20136204110003).

\section{Notes and references}

1 F. J. M. Maathuis, Curr. Opin. Plant Biol., 2009, 12, 250-258.

2 F. D. D. Bona and F. A. Monteiro, Soil Sci. Soc. Am. J., 2010, 74, 1248-1258.

3 E. Frossard, E. K. Bünemann, A. Oberson and M. A. Kertesz, Phosphorus and Sulfur in Soil, CRC Press, Boca Raton, 2012.

4 D. Kost, L. Chen and W. A. Dick, Biol. Fertil. Soils, 2008, 44, 1091-1098.

5 J. Lehmann, D. Solomon, F. J. Zhao and S. P. McGrath, Environ. Sci. Technol., 2008, 42, 3550-3555.

6 E. Marris, Nature, 2006, 442, 624-626.

7 G. Xu, Y. Lv, J. Sun, H. Shao and L. Wei, Clean: Soil, Air, Water, 2012, 40, 1093-1098.

8 S. Kuppusamy, P. Thavamani, M. Megharaj, K. Venkateswarlu and R. Naidu, Environ. Int., 2016, 87, 1-12.

9 J. Lehmann and S. Joseph, Biochar for Environmental Management: Science and Technology, Earthscan, London, 2009.
10 M. J. Gundale and T. H. De Luca, For. Ecol. Manage., 2006, 231, 86-93.

$11 \mathrm{H}$. Zheng, Z. Wang, X. Deng, S. Herbert and B. Xin, Geoderma, 2013, 206, 32-39.

12 S. Mia, J. W. Groenigen, T. F. J. Voorde, N. J. Oram, T. M. Bezemer, L. Mommer and S. Jeffery, Agric., Ecosyst. Environ., 2014, 191, 83-91.

13 N. J. Oram, T. F. J. Voorde, G.-J. Ouwehand, T. M. Bezemer, L. Mommer, S. Jeffery and J. W. V. Groenigen, Agric., Ecosyst. Environ., 2014, 191, 92-98.

14 H. Zhang, C. Chen, E. M. Gray, S. E. Boyd, H. Yang and D. Zhang, Geoderma, 2016, 276, 1-6.

15 T. Wang, M. C. Arbestain, M. Hedley and P. Bishop, Org. Geochem., 2012, 51, 45-54.

16 A. Mukherjee and A. R. Zimmerman, Geoderma, 2013, 193194, 122-130.

17 T. Qian, X. Zhang, J. Hu and H. Jiang, Chemosphere, 2013, 93, 2069-2075.

18 H. Zheng, Z. Wang, X. Deng, J. Zhao, Y. Luo, J. Novak, S. Herbert and B. Xing, Bioresour. Technol., 2013, 130, 463471.

19 C.-P. Chen, C.-H. Cheng, Y.-H. Huang, C.-T. Chen, C.-M. Lai, O. V. Menyailo, L.-J. Fan and Y.-W. Yang, Geoderma, 2014, 232-234, 581-588.

20 R. S. Jassal, M. S. Johnson, M. Molodovskaya, T. A. Black, A. Jollymore and K. Sveinson, J. Environ. Manage., 2015, 152, 140-144.

21 Y. Wang, Y. Lin, P. C. Chiu, P. T. Imhoff and M. Guo, Sci. Total Environ., 2015, 512-513, 454-463.

22 G. Bekiaris, C. Peltre, L. S. Jensen and S. Bruun, Spectrochim. Acta, Part A, 2016, 168, 29-36.

23 I. I. Manolikaki, A. Mangolis and E. Diamadopoulos, J. Environ. Manage., 2016, 181, 536-543.

24 F. Schneider and S. B. Haderlein, Geoderma, 2016, 277, 8390.

25 S. Bruun, S. L. Harmer, G. Bekiaris, W. Christel, L. Zuin, Y. Hu, L. S. Jensen and E. Lombi, Chemosphere, 2017, 169, 377-386.

26 J. N. Knudsen, P. A. Jensen, W. Lin, F. J. Frandsen and K. Dam-Johnson, Energy Fuels, 2004, 18, 810-819.

27 S. C. Blum, J. Lehmann, D. Solomon, E. F. Caires and L. R. F. Alleoni, Geoderma, 2013, 200-201, 156-164.

28 S. Cheah, S. C. Malone and C. J. Feik, Environ. Sci. Technol., 2014, 48, 8474-8480.

29 ASTM International, 2012, ASTM D2492-02 (2012): Standard Test Method for Forms of Sulfur in Coal, ASTM International, West Conshohocken, 2012.

30 S. Chattaraj and A. K. Das, Analyst, 1992, 117, 413-416.

31 C. Tan, Z. Yaxin, W. Hongtao, L. Wenjing, Z. Zeyu, Z. Yuancheng and R. Lulu, Bioresour. Technol., 2014, 164, 47-54.

32 R. Zornoza, F. Moreno-Barriga, J. A. Acosta, M. A. Muñoz and A. Faz, Chemosphere, 2016, 144, 122-130.

33 H. Yuan, T. Lu, Y. Wang, H. Huang and Y. Chen, J. Anal. Appl. Pyrolysis, 2014, 110, 277-284.

34 P. Cely, G. Gascó, J. Paz-Ferreiro and A. Méndez, J. Anal. Appl. Pyrolysis, 2015, 111, 173-182. 
35 P. Filippis, A. D. Palma, E. Petrucci, M. Scarsella and N. Verdone, Chem. Eng. Trans., 2013, 32, 205-210.

36 K. B. Cantrell, P. G. Hunt, M. Uchimiya, J. M. Novak and K. S. Ro, Bioresour. Technol., 2012, 107, 419-428.

37 M. I. Al-Wabel, A. Al-Omran, A. H. El-Naggar, M. Nadeem and A. R. A. Usman, Bioresour. Technol., 2013, 131, 374-379.

38 X. Liu, Y. Zhang, Z. Li, R. Feng and Y. Zhang, Bioresour. Technol., 2014, 170, 76-82.
39 P. Devi and A. K. Saroha, Bioresour. Technol., 2015, 192, 312320.

40 J. N. Knudsen, P. A. Jensen and K. Dam-Johansen, Energy Fuels, 2004, 18, 1385-1399.

41 G. C. Barrett, Chemistry and Biochemistry of Amino Acids, Chapman and Hall, London, 1985.

42 D. L. Sparks, Environmental Soil Chemistry, Academic Press, Amsterdam, 2rd edn, 2003. 